\title{
Surgical treatment of temporomandibular joint ankylosis: Follow-up of 15 cases and literature review
}

\author{
Belmiro Cavalcanti do Egito Vasconcelos ${ }^{1}$, Gabriela Granja Porto ${ }^{2}$, Ricardo Viana Bessa-Nogueira ${ }^{2}$, Mirella Marques \\ Mercês do Nascimento $^{3}$
}

(1) Senior Lecturer in Oral and Maxillofacial Surgery. Director of the Master and PhD Programs in Oral and Maxillofacial Surgery, University of Pernambuco (Recife-Brazil)

(2) Postgraduate Student of the PhD Program in Oral and Maxillofacial Surgery, University of Pernambuco (Recife-Brazil).

(3) Postgraduate Student of the MSc Program in Oral and Maxillofacial Surgery, University of Pernambuco (Recife-Brazil)

Correspondence:

Dr. B. Vasconcelos

Faculdade de Odontologia de Pernambuco

Universidade Pernambuco

Departamento de Cirurgia e Traumatologia BMF

Av. General Newton Cavalcanti, 1650 Camaragibe-PE

54753-220 Brazil

belmiro@pesquisador.cnpq.br

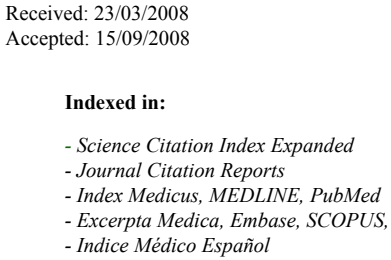

\begin{abstract}
Introduction: Ankylosis may be defined as the fusion of the articular surfaces with bony or fibrous tissue. The treatment of temporomandibular joint ankylosis poses a significant challenge because of the high incidence of recurrence.

Purpose: To report 15 cases treated by either gap arthroplasty, or the articular reconstruction technique using costochondral grafts, coronoid process grafts or alloplastic condylar implants; evaluate the results of these surgeries and make a literature review.

Methods: The sample was obtained from the records of the Oswaldo Cruz University Hospital (HUOC-UPE) of patients submitted to ankylosis treatment by alloplastic or autogenous graft between March 2000 and October 2006. Pre- and postoperative assessment included a thorough history and physical examination to determine the cause of ankylosis, the maximal incisal opening, etiology and type of the ankylosis, recurrence rate and presence of facial nerve paralysis.

Results: The mean maximal incisal opening in the preoperative period was $8.71+6.97 \mathrm{~mm}$ and in the postoperative period it was $28.50+8.10 \mathrm{~mm}$, the recurrence rate was $20 \%(\mathrm{n}=3)$, and always occurred in ankylosis type IV.

Conclusion: The articular reconstruction with alloplastic or autogenous grafts, or gap arthroplasty for the treatment of ankylosis is shown to be efficient in relation to the post-operative maximal incisal opening, recurrence and articular function.
\end{abstract}

Key words: Temporomandibular joint, ankylosis, surgery, review literature.

\section{Introduction}

Ankylosis of the temporomandibular joint (TMJ) is an intracapsular union of the disc-condyle complex to the temporal articular surface that restricts mandibular movements, including the fibrous adhesions or bony fusion between condyle, disc, glenoid fossa, and eminence (1). It is a serious and disabling condition that may cause problems in mastication, digestion, speech, appearance, and hygiene. It can also causes disturbances of facial and mandibular growth, and acute compromise of the airway invariably resulting in physical and psychological disability (2-5).

TMJ ankylosis is most commonly associated with trauma (13-100\%), local or systemic infection (10-49\%), or systemic disease $(10 \%)$, such as ankylosing spondylitis, rheumatoid arthritis, and psoriasis. Ankylosis can also occur as a result of TMJ surgery (6).

The treatment of TMJ ankylosis poses a significant challenge because of technical difficulties and a high incidence of 
recurrence. A variety of techniques for its treatment have been described in the literature. However, no single method has produced uniformly successful results $(3,6,7)$. In this paper, 15 cases of TMJ ankylosis with its different forms of treatment are reported. A descriptive statistical analysis of a minimum 24-month-follow-up is also presented as well as a critical literature review.

\section{Patients and Methods}

A retrospective evaluation of 15 consecutively treated patients with TMJ ankylosis was conducted at the Division of Oral and Maxillofacial Surgery of Oswaldo Cruz Hospital - University of Pernambuco, Recife-PE, Brazil, between 2000 and 2006. Patients were treated by gap arthroplasty and a total joint reconstruction with costochondral graft, coronoid process graft and methylmethacrylate prothesis.

Preoperative assessment included a thorough history and physical examination to determine the ankylosis characteristics according to age of onset of the ankylosis, age at the day of operation, sex, etiology, involvement, ankylosis type, treatment, recurrence rate, nerve injury after surgery, maximal incisal opening (MIO) and presence of facial asymmetry. The patients were examined and classified according to the House and Brackmann (8) grading system in the pre- and post-operative period, looking for any sign of facial nerve paralysis or paresthesia. The period of recovery from of any paralysis was also observed.

The ankylosis was classified according to Sawhney's classification (9) into four different types: type I when there was minimal bony fusion, but extensive fibrous adhesions around the joint; type II, when there was more bony fusion, especially at the outer edge of the joint surface, but no fusion within the more medial area of the joint; type III, when there was a bridge of bone between the mandible and the temporal bone; and type IV, when the joint was replaced by a mass of bone. Radiographic examination included panoramic radiographs and computed axial and coronal tomography (CT) to determine the extent of the ankylosis and to rule out any other cause of limited mouth opening.

- Surgical procedures

Exposure of the TMJ was done by the preauricular approach described by Ellis and Zide (10) under general anesthesia. After exposure and identification of the site of the ankylosis, aggressive excision of the fibrous and/or bony mass was carried out with round burs and chisels until the mandibular movements were achieved. Next the glenoid fossa was recontoured as necessary. For all three surgical procedures coronoidectomy on the ipsilateral side was performed. The contralateral coronoidectomy was performed only if the passive maximal opening was less than $35 \mathrm{~mm}$.

For the gap arthroplasty, in addition to this procedure, a gap of at least $15 \mathrm{~mm}$ was created between the glenoid fossa and the mandible.

For total TMJ reconstruction, after resection a methylmethacrylate prothesis, a costochondral graft or a coronoid process graft was put in place in order to reconstruct the TMJ.

In the immediate postoperative period the surgeons recommended that the patient also be followed up by a physiotherapist.

\section{Results}

Fifteen patients ( 6 females and 9 males) were submitted to TMJ ankylosis surgery, with 21 TMJs involved (Table 1). The mean follow-up period was $40.21+17.48$ months (2460 months). Nine patients had unilateral involvement and six bilateral. The mean age was $22.21+9.07$ years $(7-35$ years). Etiology included trauma ( $\mathrm{n}=5 / 33.34 \%)$, infection $(\mathrm{n}=9 / 60 \%)$ and ankylosing spondylitis $(\mathrm{n}=1 / 0.66 \%)$. Preoperative CT

Table 1. Ankylosis characteristics according to age of onset of the ankylosis, age at the day of operation, sex, etiology, involvement, ankylosis type, treatment, recurrence rate and nerve injury after surgery.

\begin{tabular}{|c|c|c|c|c|c|c|c|c|c|c|}
\hline N & Onset age & Age & Sex & Fol.-up & Etiol. & Envolv. & Ank. type & Treatment & Recur. & N. Injury \\
\hline 1 & $20 \mathrm{y}$ & 29 & $\mathrm{~F}$ & $50 \mathrm{~m}$ & Trauma & Unilat. & III & gap arthroplasty & NO & YES \\
\hline 2 & $10 \mathrm{y}$ & 19 & $\mathrm{M}$ & $48 \mathrm{~m}$ & Trauma & Unilat. & III & gap arthroplasty & NO & NO \\
\hline 3 & 15 days & 3 & $\mathrm{~F}$ & $42 \mathrm{~m}$ & Infection & Bilat. & IV & Reconstr. graft & YES & NO \\
\hline 4 & $8 \mathrm{y}$ & 16 & $\mathrm{M}$ & $33 \mathrm{~m}$ & Trauma & Bilat. & III & gap arthroplasty & NO & YES \\
\hline 5 & $2 \mathrm{y}$ & 3 & $\mathrm{M}$ & $47 \mathrm{~m}$ & Infection & Unilat. & III & gap arthroplasty & NO & NO \\
\hline 6 & $3 \mathrm{y}$ & 16 & $\mathrm{M}$ & $28 \mathrm{~m}$ & Infection & Unilat. & II & Reconstr. graft & NO & NO \\
\hline 7 & $10 \mathrm{y}$ & 16 & $\mathrm{M}$ & $66 \mathrm{~m}$ & Infection & Bilat. & IVR IIIL & gap arthroplasty & YES & NO \\
\hline 8 & $11 \mathrm{y}$ & 20 & $\mathrm{M}$ & $32 \mathrm{~m}$ & Trauma & Unilat. & III & Reconstr. proth. & NO & NO \\
\hline 9 & $3 \mathrm{y}$ & 28 & $\mathrm{~F}$ & $43 \mathrm{~m}$ & Infection & Unilat. & IV & gap arthroplasty & NO & NO \\
\hline 10 & $4 \mathrm{y}$ & 17 & $\mathrm{~F}$ & $42 \mathrm{~m}$ & Infection & Unilat. & III & Reconstr. proth. & NO & NO \\
\hline 11 & $2 \mathrm{y}$ & 20 & $\mathrm{M}$ & $30 \mathrm{~m}$ & Infection & Unilat. & III & Reconstr. graft & NO & NO \\
\hline 12 & $3 \mathrm{y}$ & 32 & $\mathrm{~F}$ & $39 \mathrm{~m}$ & Infection & Bilat. & I & gap arthroplasty & NO & NO \\
\hline 13 & $1 \mathrm{y}$ & 28 & $\mathrm{~F}$ & $49 \mathrm{~m}$ & Infection & Bilat. & IV & gap arthroplasty & NO & NO \\
\hline 14 & $16 \mathrm{y}$ & 35 & $\mathrm{M}$ & $66 \mathrm{~m}$ & Spondy. & Bilat. & IIR IVL & gap arthroplasty & YES & YES \\
\hline 15 & $11 \mathrm{y}$ & 16 & $\mathrm{M}$ & $24 \mathrm{~m}$ & Trauma & Unilat. & III & gap arthroplasty & NO & NO \\
\hline
\end{tabular}

Fol.-up= follow up; etiol.= etiology; recur.= recurrence; $n$. injury= nerve injury; $Y=y e a r s ; ~ m=m o n t h s ;$ Spondy.= ankylosing spondylitis; unilat.= unilateral; bilat.= bilateral. 
Table 2. Type of treatment according to recurrence.

\begin{tabular}{|l|cc|cc|cc|}
\hline \multirow{2}{*}{ Treatment } & \multicolumn{2}{|c|}{ TOTAL } & \multicolumn{2}{|c|}{ With recurrence } & \multicolumn{2}{|c|}{ Without recurrence } \\
& $\mathbf{N}$ & $\mathbf{\%}$ & $\mathbf{N}$ & $\mathbf{\%}$ & $\mathbf{N}$ & $\mathbf{\%}$ \\
\hline GAP ARTHROPLASTY & 10 & 66.67 & 2 & 13.33 & 8 & 50 \\
\hline RECONSTRUCTION & 5 & 33.33 & 1 & 6.67 & 4 & 30 \\
\hline
\end{tabular}

scans revealed various types of ankylosis, according to Sawhney's classification (9), type I $(n=1)$, type II $(n=1)$, type III $(n=8)$ and type IV $(n=5)$, which was confirmed after joint exposure. The presence of preoperative facial asymmetry was observed in 11 patients $(21.42 \%)$.

Three patients had signs of facial nerve paralysis $(21.42 \%)$. According to the House and Brackmann grading system (8), one was classified as grade III, which means there was a slight to moderate movement of the forehead and slight weakness with maximum effort of the mouth. This patient recovered within 3 months. Two were classified as grade IV, which means there was no movement in the forehead, incomplete closure of the eye and asymmetric mouth with maximum effort of the mouth. One of these was recovered within 3 months and the other within 11 months. Eleven patients were classified in the immediate postoperative period as grade I, which means there were no signs of facial nerve paralysis.

The mean maximal incisal opening (MIO) in the preoperative period was $8.71+6.97 \mathrm{~mm}$ and in the postoperative period it was $28.50+8.10 \mathrm{~mm}$. The mean pre- and post-operative MIO for gap arthroplasty was $8 \mathrm{~mm}$ and $27.67 \mathrm{~mm}$ respectively; and for reconstruction (graft and prosthesis) was $10 \mathrm{~mm}$ and $30 \mathrm{~mm}$. The recurrence rate was $21.42 \%(\mathrm{n}=3)$, and always occurred in ankylosis type IV. No recurrence was observed in ankylosis type I, II or III (Table 1). Table 2 shows the rate of recurrence for each type of treatment.

\section{Discussion}

The main causes of TMJ ankylosis are trauma and infection $(2,6)$. Estimates of a traumatic origin range from $26 \%$ to $75 \%$ and of infection from $44 \%$ to $68 \% 2$. Roychoudhury et al. (3) retrospectively studied 50 cases of TMJ ankylosis and showed that trauma was documented as a major etiologic factor in $86 \%$ of all cases. In the present study the main causes were infection and trauma. This may be because most of our patients were from a less well-informed population without easy access to the specialty. The ensuing ankylosis could therefore be a reflection of misdiagnosis, or nondiagnosis of condylar fractures or infections, which were not managed appropriately nor received no treatment at all.

TMJ ankylosis is a common condition, and its management is difficult (7). There is no agreed treatment, and results have been variable and often less than satisfactory $(2,3,6,7)$. The most frequently reported operations include gap arthroplasty, interpositional arthroplasty and joint reconstruction with autogenous or alloplastic materials $(2,3,6,11,12)$.
Gap arthroplasty alone gives rise to a gap between the articular cavity and the mandibular ramus and has the advantage of simplicity and short operating time (6). On the other hand it has the disadvantage of generating a pseudo-articulation, with shortening of the mandibular ramus and, in addition, it seems to increase the risk of recurrence $(3,6)$. Matsuura et al. (13) studied the functional and anatomic changes after gap arthroplasty by using animal models and showed that this procedure for TMJ ankylosis did not restore TMJ functionally and histologically to its preexisting state. In the other hand, Vasconcelos et al. (14) reported 8 cases of ankylosis (type I to IV) treated by gap arthroplasty and found no recurrence in their series with a follow up of at least 24 months. Complications such as the development of an open-bite in bilateral cases, premature occlusion on the affected side with contralateral open bite in unilateral cases, and limited mouth opening post-operatively are possible $(6,13)$. In this study out of a total of ten surgeries with this technique, there were two recurrences, probably related to the type of ankylosis in question (type IV). One of these, a case of bilateral ankylosis, had an anterior open-bite. The mean MIO increased from 8 $\mathrm{mm}$ preoperatively to $27.67 \mathrm{~mm}$ in the post-operative period, which may suggest that this technique was generally successful in the treatment of ankylosis.

Interpositional arthroplasty with autogenous or alloplastic material at the osteotomy site is a mechanism for preventing recurrence $(7,6,13)$. Various materials have been used such as skin (3), dermis (15), flaps of the temporal muscle/fascia (2), silicone $(7,13)$ and cartilage $(11)$. However, there are possible disadvantages, such as morbidity at the donor site and unpredictable resorption when autogenous material is used, and a risk of foreign body reaction when alloplastic material is used $(13,16)$. Thus, at present, there is no ideal interpositional graft. The following problems are encountered with present grafts: muscle shrinkage and fibroses, fascia lacking bulk, cartilage tending to fibrose and calcify, and alloplastic implants under functional loads disintegrating and causing foreign body giant cell reactions (4). In this study, however, no patient was treated with this technique.

TMJ reconstruction may be necessary for patients with extensive osteotomy and consequently insufficient ramus height, and can be performed with costochondral grafts, clavicular osteochondral grafts, iliac crest grafts, coronoid process grafts and alloplastic condylar implants $(7,6)$. The most widely accepted autogenous technique is a costochondral graft. According to MacIntosh (17), the advantages of this graft are 
its biological compatibility, workability and functional adaptability. The growth potential of the costochondral graft makes it the ideal choice in children $(6,18)$. Potential problems include fracture, further ankylosis, donor site morbidity and the variable growth behaviour of the graft (19). This problem could be solved using the coronoid process, which in patients with long-standing TMJ ankylosis is longer and thicker, so it could be used to take the place of the condyle and lengthen the mandibular ramus, thus avoiding a second surgical site and no increase in donor site morbidity (20). This graft has also the advantage of a predicable behavior (6).

In all patients in this study the ipsilateral coronoidectomy was performed as the coronoid process tends to grow in a long-standing ankylosis causing inadequate intraoperative interincisal opening (6). In 2 patients of this study, the ipsilateral coronoid process was used as a graft to reconstruct the TMJ. After removal and shaping of the graft, the coronoid process was positioned in order to reestablish height of the ramus. Neither patient had any signs of recurrence or limitation of mandibular movements. One patient using costochondral graft recurred, maybe because this patient had an ankylosis type IV associated with micrognathia, which was not treated at the same operation time.

To avoid these problems a number of alloplastic materials (acrylic, synthetic fibres, titanium total joint systems) and systems have been developed for use in the reconstruction of the TMJ (21). Alloplastic joints are said to allow a closer reproduction of the normal anatomy of the joint, with restoration of vertical dimension, avoidance of donor site morbidity, reduction in operation time and a lower risk of recurrent ankylosis (19). The main problems associated with these materials relate to wear at the joint surfaces, foreign body reaction, mobility of the implant with displacement, and implant fracture, caused, most of the time, by the use of inappropriate alloplastic materials $(17,22)$.

Borçbakan (23) was the first to use an acrylic condyle in the surgical treatment of TMJ ankylosis. Acrylic is a simple, inexpensive material that can be produced locally and does not require an additional surgical site. The clinician involved in this study prepared the acrylic prosthesis by hand. Acrylic does not produce any long-term complications and is well tolerated (19). The only disadvantage of the technique is the development of facial asymmetry when it is used in a child, requiring corrective jaw surgery. The two artificial joints constructed in this study were condyloid joints. The prothesis permitted opening and closing of the mouth, protrusion, retrusion and relatively good lateral excursion clinically and intraoperatively.

Irrespective of the technique chosen by the surgeon, aggressive resection of the bony or fibrous ankylotic segment is crucial to avoid recurrence. In addition, a dissection of the muscles of the mandibular ramus and ipsilateral coronoidectomy must be carried out to prevent inadequate intraoperative interincisal opening, because the coronoid process may be elongated in long-standing cases (8). If a $35 \mathrm{~mm}$ opening without force is not achieved, a contralateral intraoral coronoidectomy should be done. A reconstruction of the TMJ is ideal. After that, aggressive physiotherapy should be recommended in order to disrupt and prevent adhesions, prevent soft-tissue contractions and redevelop normal muscle function $(8,24)$. Some authors prefer to wait for a period of 5 to 7 days for pain and swelling to subside before commencing mobilization of the mandible. This delay allows early phase healing of the surrounding tissues. The potential problem with early mobilization is that it may provoke bleeding and create a large hematoma with delayed healing and an increased likelihood of wound breakdown, disorganization and ossification (4).

Regardless of the surgical approach used to gain access to the TMJ, the final dissection places the facial nerve at risk for damage $(9,25)$. A loss of function of the frontalis and orbicularis oculi muscles is always a possibility (9). The incidence of complications such as permanent injury of the facial nerve is very low $(5,26)$, with rate varying from 9 to $18 \%(27)$ and 1.5 to $32 \%$ (25), usually disappearing within 6 months. The right choice of technique for making the approach to the TMJ, such as the preauricular approach modified by Alkayat and Bramley(28) and the preauricular approach described by Ellis $\&$ Zide (10), when properly performed, may decrease the risk of damaging this nerve (4). All nerve damage in this study occurred in ankylosis type III treated by gap arthroplasty with an incidence of $21.42 \%$; two of these patients recovered within 3 months and the other within 11 months. It is possible that the difficulty of the surgical procedure in relation to the type of ankylosis may increase the risks of damage to the facial nerve, especially because the longer the duration of surgery, the longer tissues are separated, thereby increasing the risk of such damage.

The articular reconstruction with alloplastic or autogenous grafts, or gap arthroplasty for the treatment of ankylosis is shown to be efficient in relation to the post-operative maximal incisal opening, recurrence and articular function.

Since the majority of the published studies on humans are case series, it is necessary to conduct studies with the same type of ankylosis and operative technique containing a larger sample in order to permit comparisons of the various forms of treatment.

\section{References}

1. Long X, Li X, Cheng Y, Yang X, Qin L, Qiao Y, et al. Preservation of disc for treatment of traumatic temporomandibular joint ankylosis. J Oral Maxillofac Surg. 2005 Jul;63(7):897-902.

2. Chidzonga MM. Temporomandibular joint ankylosis: review of thirty-two cases. Br J Oral Maxillofac Surg. 1999 Apr;37(2):123-6.

3. Roychoudhury A, Parkash H, Trikha A. Functional restoration by gap arthroplasty in temporomandibular joint ankylosis: a report of 50 cases. Oral Surg Oral Med Oral Pathol Oral Radiol Endod. 1999 Feb;87(2):166-9.

4. Su-Gwan K. Treatment of temporomandibular joint ankylosis with temporalis muscle and fascia flap. Int J Oral Maxillofac Surg. 2001 Jun;30(3):189-93.

5. Güven O. Treatment of temporomandibular joint ankylosis by a modified fossa prosthesis. J Craniomaxillofac Surg. 2004 Aug;32(4):236-42.

6. Kaban LB, Perrott DH, Fisher K. A protocol for management of temporomandibular joint ankylosis. J Oral Maxillofac Surg. 1990 Nov;48(11):1145-51. 
7. Erdem E, Alkan A. The use of acrylic marbles for interposition arthroplasty in the treatment of temporomandibular joint ankylosis: follow-up of 47 cases. Int J Oral Maxillofac Surg. 2001 Feb;30(1):32-6.

8. House JW, Brackmann DE. Facial nerve grading system. Otolaryngol Head Neck Surg. 1985 Apr;93(2):146-7.

9. Schobel G, Millesi W, Watzke IM, Hollmann K. Ankylosis of the temporomandibular joint. Follow-up of thirteen patients. Oral Surg Oral Med Oral Pathol. 1992 Jul;74(1):7-14.

10. Ellis E, Zide MF. Surgical approaches to the facial skeleton. 1th ed. Media: Lippincott Williams \& Wilkins; 1995

11. Lei Z. Auricular cartilage graft interposition after temporomandibular joint ankylosis surgery in children. J Oral Maxillofac Surg. 2002 Sep;60(9):985-7.

12. Manganello-Souza LC, Mariani PB. Temporomandibular joint ankylosis: report of 14 cases. Int J Oral Maxillofac Surg. 2003 Feb;32(1):24-9.

13. Matsuura H, Miyamoto H, Ogi N, Kurita K, Goss AN. The effect of gap arthroplasty on temporomandibular joint ankylosis: an experimental study. Int J Oral Maxillofac Surg. 2001 Oct;30(5):431-7.

14. Vasconcelos BC, Bessa-Nogueira RV, Cypriano RV. Treatment of temporomandibular joint ankylosis by gap arthroplasty. Med Oral Patol Oral Cir Bucal. 2006 Jan 1;11(1):E66-9.

15. Dimitroulis G. The interpositional dermis-fat graft in the management of temporomandibular joint ankylosis. Int J Oral Maxillofac Surg. 2004 Dec;33(8):755-60.

16. Saeed NR, Kent JN. A retrospective study of the costochondral graft in TMJ reconstruction. Int J Oral Maxillofac Surg. 2003 Dec;32(6):606-9.

17. MacIntosh RB. The use of autogenous tissues for temporomandibular joint reconstruction. J Oral Maxillofac Surg. 2000 Jan;58(1):63-9.

18. Ko EW, Huang CS, Chen YR. Temporomandibular joint reconstruction in children using costochondral grafts. J Oral Maxillofac Surg. 1999 Jul;57(7):789-98.

19. Saeed N, Hensher R, McLeod N, Kent J. Reconstruction of the temporomandibular joint autogenous compared with alloplastic. Br J Oral Maxillofac Surg. 2002 Aug;40(4):296-9.

20. Hong Y, Gu X, Feng X, Wang Y. Modified coronoid process grafts combined with sagittal split osteotomy for treatment of bilateral temporomandibular joint ankylosis. J Oral Maxillofac Surg. 2002 Jan;60(1):11-8.

21. Van Loon JP, De Bont GM, Boering G. Evaluation of temporomandibular joint prostheses: review of the literature from 1946 to 1994 and implications for future prosthesis designs. J Oral Maxillofac Surg. 1995 Sep;53(9):984-96.

22. Speculand B, Hensher R, Powell D. Total prosthetic replacement of the TMJ: experience with two systems 1988-1997. Br J Oral Maxillofac Surg. 2000 Aug;38(4):360-9.

23. Borcbakan C. The use of an acrylic condyle in temporomandibular ankylosis. Rev Stomatol Chir Maxillofac. 1968 Oct-Nov;69(7):600-3.

24. Qudah MA, Qudeimat MA, Al-Maaita J. Treatment of TMJ ankylosis in Jordanian children - a comparison of two surgical techniques. J Craniomaxillofac Surg. $2005 \mathrm{Feb}$;33(1):30-6.

25. Politi M, Toro C, Cian R, Costa F, Robiony M. The deep subfascial approach to the temporomandibular joint. J Oral Maxillofac Surg. 2004 Sep;62(9):1097-102.

26. Mikkonen P, Lindqvist C, Pihakari A, Iizuka T, Paukku P. Osteotomyosteosynthesis in displaced condylar fractures. Int J Oral Maxillofac Surg. 1989 Oct;18(5):267-70.

27. Weinberg S, Kryshtalskyj B. Facial nerve function following temporomandibular joint surgery using the preauricular approach. J Oral Maxillofac Surg. 1992 Oct;50(10):1048-51.

28. Hall MB, Brown RW, Lebowitz MS. Facial nerve injury during surgery of the temporomandibular joint: a comparison of two dissection techniques. J Oral Maxillofac Surg. 1985 Jan;43(1):20-3. 